See discussions, stats, and author profiles for this publication at: https://www.researchgate.net/publication/224810019

\title{
Rat liver mitochondrial damage under acute or chronic carbon tetrachloride- induced intoxication: Protection by melatonin and cranberry flavonoids
}

Article in Toxicology and Applied Pharmacology · April 2012

Dol: 10.1016/j.taap.2012.04.007 · Source: PubMed

CITATIONS

39

7 authors, including:

Iosif Karlovitch Dremza

Grodno State Medical University

14 PUBLICATIONS 144 CITATIONS

SEE PROFILE

Ilyai B Zavodnik

Yanka Kupala State University of Grodno

102 PUBLICATIONS 1,202 CITATIONS

SEE PROFILE
READS

65

Russel J Reiter

University of Texas Health Science Center at San Antonio 1,619 PUBLICATIONS 103,771 CITATIONS

SEE PROFILE

Some of the authors of this publication are also working on these related projects:

Project Melatonin as a potent therapeutic alternative for different pathophysiological conditions View project

Project Breast cancer cells: Modulation by melatonin and the ubiquitin-proteasome system - A review View project 
Provided for non-commercial research and education use. Not for reproduction, distribution or commercial use.

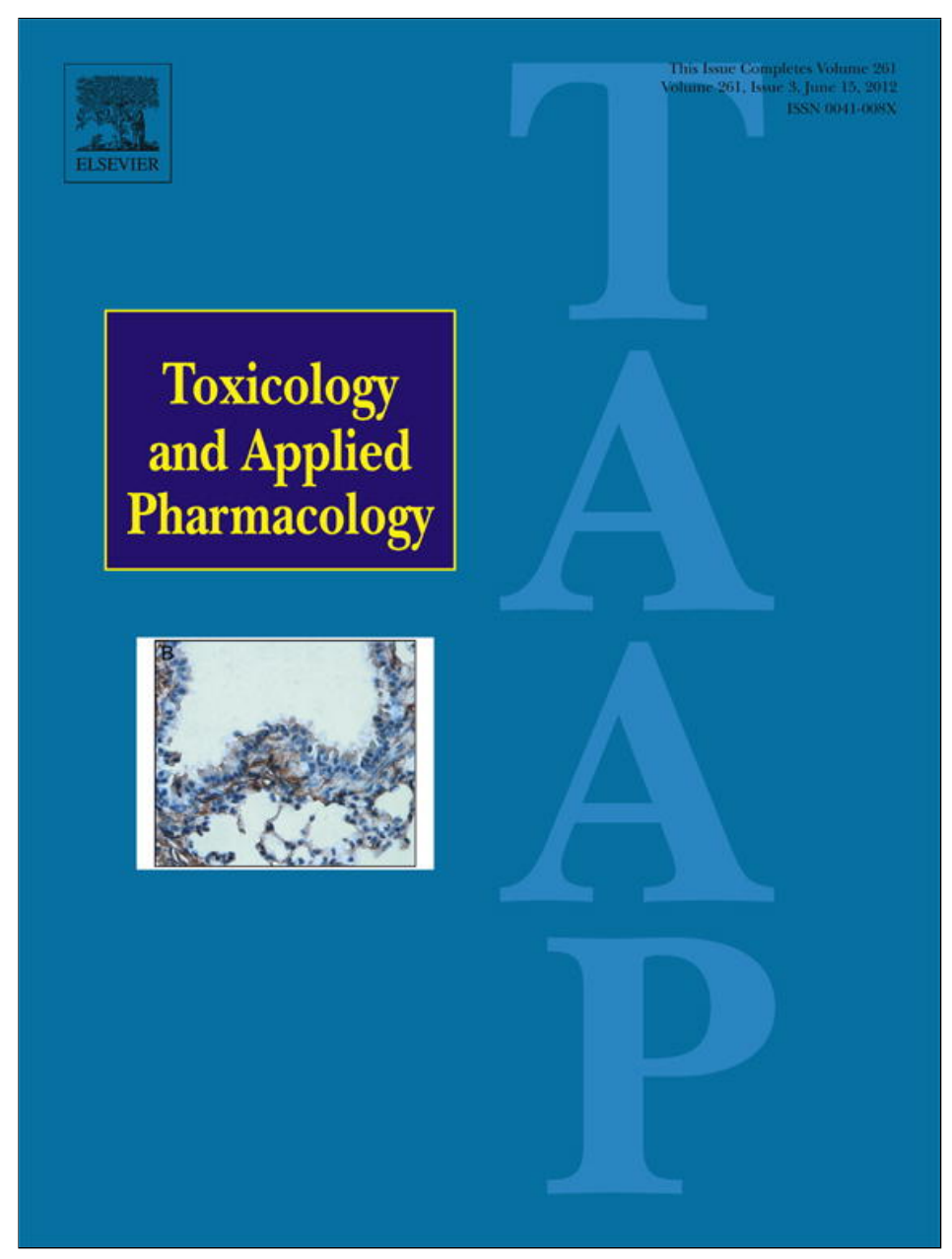

This article appeared in a journal published by Elsevier. The attached copy is furnished to the author for internal non-commercial research and education use, including for instruction at the authors institution and sharing with colleagues.

Other uses, including reproduction and distribution, or selling or licensing copies, or posting to personal, institutional or third party websites are prohibited.

In most cases authors are permitted to post their version of the article (e.g. in Word or Tex form) to their personal website or institutional repository. Authors requiring further information regarding Elsevier's archiving and manuscript policies are encouraged to visit:

http://www.elsevier.com/copyright 


\title{
Rat liver mitochondrial damage under acute or chronic carbon tetrachloride-induced intoxication: Protection by melatonin and cranberry flavonoids
}

\author{
V.T. Cheshchevik a,b, E.A. Lapshina a , I.K. Dremza a , S.V. Zabrodskaya ${ }^{\text {a }}$, R.J. Reiter ${ }^{\text {c }}$, \\ N.I. Prokopchik ${ }^{\mathrm{d}}$, I.B. Zavodnik ${ }^{\mathrm{a}, \mathrm{b}, *}$ \\ a Institute for Pharmacology and Biochemistry, National Academy of Sciences of Belarus, Len. Kom. Blvd. - 50, 230017 Grodno, Belarus \\ ${ }^{\mathrm{b}}$ Department of Biochemistry, Yanka Kupala Grodno State University, Len. Kom. Blvd. - 50, 230017 Grodno, Belarus \\ c Department of Cellular and Structural Biology, University of Texas Health Science Center, 7703 Floyd Curl Drive, San Antonio, TX 78229-3900, USA \\ ${ }^{\mathrm{d}}$ Grodno State Medical University, Gorkogo - 80, 230015 Grodno, Belarus
}

\section{A R T I C L E I N F O}

\section{Article history:}

Received 27 January 2012

Revised 30 March 2012

Accepted 5 April 2012

Available online 14 April 2012

\section{Keywords:}

Mitochondria

Liver

Intoxication

Melatonin

Cranberry flavonoids

\begin{abstract}
A B S T R A C T
In current societies, the risk of toxic liver damage has markedly increased. The aim of the present work was to carry out further research into the mechanism(s) of liver mitochondrial damage induced by acute $(0.8 \mathrm{~g} / \mathrm{kg}$ body weight, single injection) or chronic ( $1.6 \mathrm{~g} / \mathrm{kg}$ body weight, 30 days, biweekly injections) carbon tetrachloride - induced intoxication and to evaluate the hepatoprotective potential of the antioxidant, melatonin, as well as succinate and cranberry flavonoids in rats.

Acute intoxication resulted in considerable impairment of mitochondrial respiratory parameters in the liver. The activity of mitochondrial succinate dehydrogenase (complex II) decreased (by $25 \%, \mathrm{p}<0.05$ ). Short-term melatonin treatment ( $10 \mathrm{mg} / \mathrm{kg}$, three times) of rats did not reduce the degree of toxic mitochondrial dysfunction but decreased the enhanced NO production.

After 30-day chronic intoxication, no significant change in the respiratory activity of liver mitochondria was observed, despite marked changes in the redox-balance of mitochondria. The activities of the mitochondrial enzymes, succinate dehydrogenase and glutathione peroxidase, as well as that of cytoplasmic catalase in liver cells were inhibited significantly. Mitochondria isolated from the livers of the rats chronically treated with $\mathrm{CCl}_{4}$ displayed obvious irreversible impairments. Long-term melatonin administration $(10 \mathrm{mg} / \mathrm{kg}$, 30 days, daily) to chronically intoxicated rats diminished the toxic effects of $\mathrm{CCl}_{4}$, reducing elevated plasma activities of alanine aminotransferase and aspartate aminotransferase and bilirubin concentration, prevented accumulation of membrane lipid peroxidation products in rat liver and resulted in apparent preservation of the mitochondrial ultrastructure. The treatment of the animals by the complex of melatonin $(10 \mathrm{mg} / \mathrm{kg})$ plus succinate $(50 \mathrm{mg} / \mathrm{kg}$ ) plus cranberry flavonoids $(7 \mathrm{mg} / \mathrm{kg})$ was even more effective in prevention of toxic liver injury and liver mitochondria damage.
\end{abstract}

(c) 2012 Elsevier Inc. All rights reserved.

\section{Introduction}

The risk of toxic liver damage has markedly increased in recent years due to the exposure to environmental toxins, pesticides and chemotherapeutics. Many compounds, including useful drugs, can cause liver cell damage through their metabolic conversion to highly reactive substances and the generation of free radicals (Mahesh et al., 2010).

Carbon tetrachloride continues to provide an important service as a model substance to elucidate the mechanisms of action of hepatotoxic agents (Weber et al., 2003). The mechanism(s) of $\mathrm{CCl}_{4}$-induced pathological processes in the cell have been widely studied (Mahesh et al., 2010; Shiryaeva et al., 2009; Smucler, 1976). It is well known

* Corresponding author at: Department of Biochemistry, Yanka Kupala Grodno State University, Blvd. Len. Kom. - 50, 230017 Grodno, Belarus. Fax: +375 152434121.

E-mail address: zavodnik_il@mail.ru (I.B.ZZavodnik). that $\mathrm{CCl}_{4}$ is activated by cytochromes CYP2E1, CYP2B1 or CYP2B2, and, possibly, CYP3A to form the trichloromethyl radical $\mathrm{CCl}_{3}^{*}$ which, in the presence of $\mathrm{O}_{2}$, is subsequently converted into a highly reactive trichloromethylperoxyl radical $\mathrm{CCl}_{3} \mathrm{OO}^{*}$ (Weber et al., 2003; Manibusan et al., 2007). Under activation of Kupffer cells (stellate cells) by toxic agents, free radicals and nitric oxide (NO) they migrate to the inflammation sites of the liver, synthesize transforming growth factor (TGF) $\beta$ and extracellular matrix, which results in fibrogenesis. Production and release of cytokines and other mediators by Kupffer cells in response to toxins initiate a cascade of events that can culminate in altered liver homeostasis and hepatocyte injury (Ju et al., 2002).

At the molecular level, $\mathrm{CCl}_{4}$ activates tumor necrosis factor (TNF) $\alpha$, NO, TGF $\alpha$ and TGF $\beta$ synthesis in the cell, processes that appear to direct the cell primarily toward self-destruction or fibrosis (Weber et al., 2003). Interleukins (IL-6 or IL-10), on the contrary, have the potential to initiate recovery of the $\mathrm{CCl}_{4}$-damaged hepatocytes. In a chronic liver damage, a vicious circle of hepatocyte injury, reactive oxygen species 
production, inflammatory cell recruitment and hepatic stellate cell activation occurs, amplifying the fibrogenic response (Mitchell et al., 2009). It was suggested that reactive metabolite formation, gluthatione depletion, outer mitochondrial membrane pore formation by Bcl-2 family members, Bax and Bid, intramembrane protein release, e.g. apoptosisinducing factor and endonuclease $G$ and the diminished capacity to ATP synthesis, are critical events in hepatotoxicity (Jaeschke and Bajt, 2006). Based on the dose, exposure time and the presence of potentiating agents, tissue regeneration can take place with recovery from liver damage (Weber et al., 2003).

Hepatocyte mitochondrial dysfunction and subsequent oxidative stress play significant pathophysiological roles at the early steps of fibrogenesis (Mitchell et al., 2009). However, the specific role of hepatocyte mitochondrial dysfunction in the fibrogenetic process is still unknown.

Pharmacological correction and prevention of toxic liver damage using safe and effective "biocorrectors" with both a wide range of pharmacological activities and high specificity to the target are a major concern of contemporary medicine. Several of the $\mathrm{CCl}_{4}$ - induced intoxication processes can be specifically interrupted with the use of antioxidants and mitogens, respectively, by restoring cellular methylation, or by preserving calcium sequestration (Weber et al., 2003). Essential fatty acids for regeneration of hepatocyte membrane structure, hypocholesterinemic agents, antioxidants, anti-inflammatory substances, detoxifying agents and plant-derived natural products, such as flavonoids, terpenoids and steroids, have received considerable attention in recent years in the pharmacotherapy of liver damages due to their diverse pharmacological and biochemical activities (Mahesh et al., 2010). This study provides further information about the mechanism(s) of liver mitochondrial injury induced by the known hepatotoxic agent, $\mathrm{CCl}_{4}$, and about the efficacy of the antioxidant melatonin and cranberry flavonoids in reducing the hepatotoxicity.

\section{Materials and methods}

Reagents. $\quad \mathrm{N}$ - acetyl-5-methoxytriptamine (melatonin), succinic acid disodium salt hexahydrate, L-glutamic acid sodium salt, L-malic acid sodium salt, ADP, 5,5'-dithiobis (2-nitrobenzoic acid) (Ellman's reagent), trichloroacetic acid (TCA), NADH, carbon tetrachloride $\left(\mathrm{CCl}_{4}\right)$, reduced glutathione (GSH), 1-chloro-2,4-dinitrobenzene (CDNB), and 2,6dichlorophenol-indophenol (DCPI) were from Sigma-Aldrich, St. Louis, MO, USA or Steinheim, Germany.

Preparation of cranberry extract. Cranberry fruits (1 kg) were dried, crushed, blended in water $(1 \mathrm{l})$ at $25^{\circ} \mathrm{C}$ and filtered through sieves and Whatman filter paper. Pigment was extracted using ethanol (0.4 l) from remaining wet hulls by maceration at $25^{\circ} \mathrm{C}$. The ethanol extract was filtered using Whatman filter paper and concentrated at $35^{\circ} \mathrm{C}$ using a rotary evaporator, suspended in water $(30 \mathrm{ml})$ and then partitioned with n-hexane $(3 \times 30 \mathrm{ml})$ to remove carotenoids, fats and waxes, followed by additional partitioning into $90 \mathrm{ml}$ of ethyl acetate to selectively extract flavanols, anthocyanins and proanthocyanidins. The ethyl acetate extract was concentrated by vacuum evaporation (7 g) and analyzed by Whatman paper chromatography in isobutanol: acetic acid: $\mathrm{H}_{2} \mathrm{O}=4: 1: 2$. Crude extract containing $700 \mathrm{mg}$ of flavanols, anthocyanins and proanthocyanidins was analyzed spectrophotometrically using the average molar extinction coefficient for flavonoids equal $14,500 \mathrm{M}^{-1} \mathrm{~cm}^{-1}$ at the region of 360-385 nm (Markham, 1975).

Animal models. The experiments were carried out on male albino Wistar rats weighing 200-250 g. Each experimental group included 8-10 animals. The animals were adapted to intermittent 12-h light (beginning at 08:00 h) and 12-h dark (beginning at 20:00 h) phases cycle for 1 week.
Acute rat intoxication with carbon tetrachloride. $\mathrm{CCl}_{4}$ at a dose of $0.8 \mathrm{~g} / \mathrm{kg}$ (50\% solution in olive oil) was administered singly intragastrically (i.g) via a gastric tube at $9 \mathrm{~h}$. Melatonin $(10 \mathrm{mg} / \mathrm{kg})$ as a $0.3 \%$ solution in a $0.9 \% \mathrm{NaCl}$ solution containing $5 \%$ ethanol was injected intraperitoneally (i.p.) three times: 30 min prior to $\mathrm{CCl}_{4}$ treatment and 2 and $6 \mathrm{~h}$ following the treatment. The animals were subdivided into 4 groups:

1) controls, rats treated with olive oil (i.g., $1.0 \mathrm{ml} / \mathrm{kg}$ b.w.) and a physiologic solution containing 5\% ethanol (i.p. in the same volume as the melatonin solution);2) melatonin, rats treated with melatonin, i.p., and olive oil, i.g.; 3) $\mathrm{CCl}_{4}$, rats treated with $\mathrm{CCl}_{4}$, i.g., and physiological solution, i.p.; and 4) melatonin $+\mathrm{CCl}_{4}$, the animals treated with melatonin and carbon tetrachloride. The rats were decapitated after $24 \mathrm{~h}$ following the $\mathrm{CCl}_{4}$ administration. Animals were sacrificed according to the rules defined by the European Convention for the Protection of Vertebrate Animals Used for Experimental and Other Scientific Purposes and the study was approved by the Ethics Committee of the Institute for Pharmacology and Biochemistry of the National Academy of Sciences of Belarus.

Chronic rat intoxication with carbon tetrachloride. The rats were subdivided into 5 groups. The first group served as controls and received a subcutaneous injection (s.c.) of olive oil $(2.0 \mathrm{ml} / \mathrm{kg}$ b.w., 30 days, twice a week) and a physiologic solution containing $5 \%$ ethanol (i.g. in the same volume as the melatonin solution). The second group received an injection of $\mathrm{CCl}_{4}(1.6 \mathrm{~g} / \mathrm{kg}$ b.w., 30 days, twice a week, as a $50 \%$ solution in olive oil, s.c.) at $9 \mathrm{~h}$ and a physiologic solution (i.g., 30 days, every day) at $20 \mathrm{~h}$. The third, fourth and fifth groups were given melatonin $(10 \mathrm{mg} / \mathrm{kg}$ b.w., 30 days, i.g.); melatonin and succinate $(50 \mathrm{mg} / \mathrm{kg}$ b.w., 30 days, i.g.); melatonin, succinate and cranberry flavonoids ( $7 \mathrm{mg} / \mathrm{kg}$ b.w., 30 days, i.g.), respectively. The animals were sacrificed by decapitation 24 hours after last $\mathrm{CCl}_{4}$ injection. Blood was collected and the activity of serum aminotransferases [(alanine aminotransferase (ALT) and aspartate aminotransferase (AST)] as well as total, free and conjugated bilirubin levels in blood plasma were measured.

Isolation of mitochondria and measurement of their respiratory activity. The liver was removed in cold $\left(0-4{ }^{\circ} \mathrm{C}\right)$ isotonic phosphate buffer ( $150 \mathrm{mM} \mathrm{NaCl}, 10 \mathrm{mM} \mathrm{Na}_{2} \mathrm{HPO}_{4}, \mathrm{pH}$ 7.4), dried with filter paper, weighed and homogenized in the medium containing $0.25 \mathrm{M}$ sucrose, $0.02 \mathrm{M}$ Tris- $\mathrm{HCl}$ and $0.001 \mathrm{M}$ EDTA, pH 7.2. Mitochondria were isolated by the method of differential centrifugation (Johnson and Lardy, 1967). The homogenate was centrifuged at $600 \mathrm{~g}$ for $10 \mathrm{~min}\left(\right.$ at $4{ }^{\circ} \mathrm{C}$ ) for nuclear precipitation. The supernatant was centrifuged at $8,500 \mathrm{~g}$ for $10 \mathrm{~min}$ (at $4{ }^{\circ} \mathrm{C}$ ). The mitochondrial pellet was washed twice in the isolation medium and resuspended to a protein concentration of $35-40 \mathrm{mg} / \mathrm{ml}$. The protein concentration was determined according to Lowry et al. (1951).

The mitochondrial respiratory rate was measured polarographically at $26.5^{\circ} \mathrm{C}$ using a laboratory-made oxygen Clark-type electrode and a hermetic polarographic cell. The mitochondrial pellet was placed in a cell with the incubation medium containing $0.125 \mathrm{M}$ sucrose, $0.02 \mathrm{M}$ Tris- $\mathrm{HCl}, 0.05 \mathrm{M} \mathrm{KCl}, 0.02 \mathrm{M} \mathrm{KH}_{2} \mathrm{PO}_{4}, 0.005 \mathrm{M} \mathrm{MgSO}$, and $0.001 \mathrm{M}$ EDTA, pH 7.5. The respiratory substrates, such as L-glutamate $(5 \mathrm{mM})+\mathrm{L}$ - malate $(2 \mathrm{mM})$ and succinate $(5 \mathrm{mM})$, and ADP $(180 \mu \mathrm{M}$, this corresponded to $210 \mathrm{nmol}$ ADP in the polarographic cell), were introduced into the mitochondrial suspension. The mitochondrial respiratory rate was determined in different metabolic states: $V_{1}$ was the endogenous oxygen consumption rate, $\mathrm{V}_{2}$ was the substrate-dependent respiratory rate, $V_{3}$ was the rate of respiration coupled with phosphorylation (after addition of $\mathrm{ADP}$ ) and $\mathrm{V}_{4}$ was the rate of oxidation after phosphorylation. The parameters for coupling of mitochondrial oxidation and phosphorylation were determined: the acceptor control ratio $(\mathrm{ACR})\left(\mathrm{V}_{3} / \mathrm{V}_{2}\right)$, the respiratory control ratio (RCR) $\left(\mathrm{V}_{3} / \mathrm{V}_{4}\right)$ and the coefficient of phosphorylation (ADP/O). 
Biochemical measurements. The reduced glutathione content (GSH) and protein SH-groups level (PSH) in the liver tissue and the hepatocyte mitochondrial fraction were measured according to Ellman (1959), using the molar extinction coefficient.

$\varepsilon_{412}=13,600 \mathrm{M}^{-1} \mathrm{~cm}^{-1}$. Mixed disulfides formed by glutathione and accessible sulfhydryl groups of mitochondrial proteins (PSSG) were determined by the method described by Rossi et al. (1993). The accumulated products of membrane lipid peroxidation (thiobarbituric acid-reactive substances, TBARS) were monitored assuming that the molar absorption coefficient $\varepsilon_{532}=1.5610^{5} \mathrm{M}^{-1} \mathrm{~cm}^{-1}$ (Stocks and Dormandy, 1971). Before mitochondrial enzyme activity measurements $0.1 \mathrm{ml}$ mitochondrial pellet was resuspended in $0.2 \mathrm{ml} \mathrm{H}_{2} \mathrm{O}$ and subjected to 3 cycles of freeze-thawing (Zoccarato et al., 2004). The activity of glutathione peroxidase (GPx) in the mitochondrial pellet was measured by the method of Martinez et al. (1979). The activity of mitochondrial glutathione-S-transferase (GST) was determined employing the method of Habig et al. (1974). The activity of mitochondrial succinate dehydrogenase $(\mathrm{SDH})$ was determined by the rate of 2,6 - dichlorophenol-indophenol reduction, whereas that of $\alpha$-ketoglutarate dehydrogenase - by the rate of $\mathrm{NAD}^{+}$reduction (Nulton-Persson and Szweda, 2001). The activities of the marker enzymes of hepatic cell membrane injury, ALT and AST, as well the levels of free, conjugated and total bilirubin in blood plasma were determined using reagent kits from Pliva-Lachema a.s., Brno, Czech Republic. The overall level of nitrites and nitrates reflecting nitric oxide generation was measured in blood plasma using the Griess reagent (N- (1-naphtyl) ethylenediamine dihydrochloride, sulfanilamide) and metallic cadmium as a reducer (Green et al., 1982).

Morphological measurements. For histopathology, the liver was immediately removed, weighed, sliced into 2- to 3- $\mathrm{mm}$ sections, and fixed in $10 \%$ neutral buffered formalin. After $48 \mathrm{~h}$ of fixation, tissues were paraffin-infiltrated. Histological sections $(4 \mu \mathrm{m})$ were prepared with a microtome, mounted on glass slides and stained with hematoxylin and eosin (H\&E) and observed under a light microscope (Carl Zeiss Jena, Germany). Each microphotograph is a representative image of liver tissue of 8-10 animals that showed the same phenotype.

Electron microscopy analysis of rat liver mitochondria. Mitochondrial ultrastructure analysis was performed on isolated mitochondria from 3 animals of each group using the method of electron microscopy. Isolated mitochondria suspensions were centrifuged at $5,000 \mathrm{~g}$ at $4{ }^{\circ} \mathrm{C}$ for $5 \mathrm{~min}$ and the pellet of mitochondria was fixed by $2.5 \%$ glutaric aldehyde in Millonig's buffer, $\mathrm{pH} 7.4$, at $4{ }^{\circ} \mathrm{C}$ for 4 hours, then washed with the same buffer and postfixed by $1 \% \mathrm{OsO}_{4}$ solution in Millonig's buffer, $\mathrm{pH} 7.4$, at $4^{\circ} \mathrm{C}$ for 2 hours. The samples were dehydrated by rinsing them in ethanol and acetone and embedding them in an eponaraldite mixture (Gabriel, 1982). Ultrathin sections were prepared with an MT-7 000 ULTRA ultratome (USA) and were contrasted with $2 \%$ uranyl acetate in $50 \%$ methanol (Watson, 1958) and lead citrate (Reynolds, 1963). They were examined using a JEM-1011 electron microscope (Japan) at magnifications of 5,000x - 40,000x. The microphotographs of mitochondria were made by an Olympus MegaView III camera (Germany).

Statistical analysis. Data for 8-10 rats in each group are presented as a mean $\pm S D$ for the normally distributed parameters. We used the standard Student's $t$-test for the comparison of data showing no departures from normality according to Shapiro-Wilk's test. $\mathrm{P}<0.05$ was taken to indicate statistical significance. The calculations were performed using the statistical software Statistica 6.0.

\section{Results}

In the present work, we evaluated the parameters of mitochondrial physiology, metabolic state and mitochondrial structure after chronic or acute intoxication by carbon tetrachloride and melatonin and cranberry flavonoids treatment in rats.

\section{Chronic rat intoxication}

Mitochondrial effects of chronic intoxication and melatonin, succinate and cranberry flavonoids administration. Under chronic rat intoxication we observed some increase in the substrate-dependent respiration rate $\mathrm{V}_{2}$ (by $25 \%, \mathrm{p}<0.05$ ), ADP-stimulated oxygen consumption rate $\mathrm{V}_{3}$ (by $15 \%, \mathrm{p}<0.05$ ) and the respiration rate after ADP consumption $\mathrm{V}_{4}$ (by $20 \%, \mathrm{p}<0.05$ ) in the case of succinate, but not glutamate, as respiratory substrate (Fig. 1A). With both substrates, the acceptor and respiratory control ratios and the phosphorylation coefficient did not change during intoxication in the case of both substrates (Fig. 1B). 30-day melatonin administration ( $10 \mathrm{mg} / \mathrm{kg}, 30$ days, daily), combined administration of succinate $(50 \mathrm{mg} / \mathrm{kg}$ ) and melatonin or the treatment of the animals by the complex of melatonin $(10 \mathrm{mg} / \mathrm{kg})$ plus succinate $(50 \mathrm{mg} / \mathrm{kg}$ ) plus crude cranberry flavonoid extract $(7 \mathrm{mg} / \mathrm{kg})$ did not influence all the respiratory parameters (Fig. 1).

There was a significant change in the redox state of mitochondria: the level of mitochondrial reduced glutathione (GSH) was enhanced considerably (by $60 \%, \mathrm{p}<0.01$ ) after 30 days of intoxication (Table 1 ). Melatonin administration diminished the augmented level of mitochondrial glutathione (by $20 \%, \mathrm{p}<0.05$ ). The combined administration of succinate and melatonin or the treatment by the combination of melatonin plus succinate plus crude cranberry flavonoid extract for 30 days did not influence the GSH levels in mitochondria. An increased level of mixed protein - glutathione disulfides (GSSP) in mitochondria
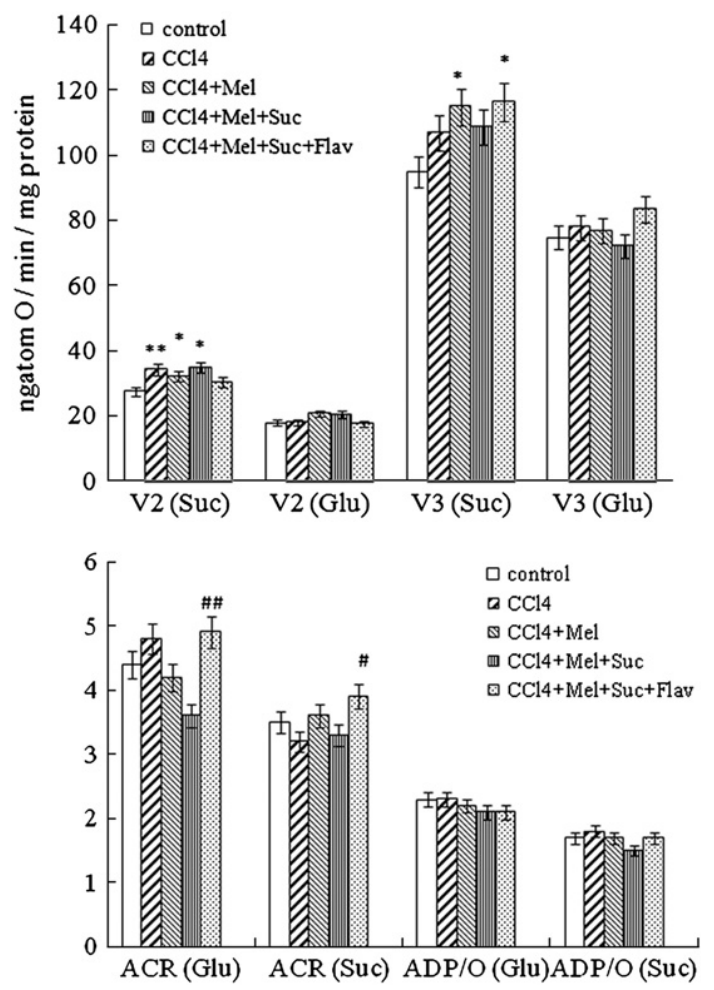

Fig. 1. Parameters of oxidative phosphorylation processes in rat liver mitochondria under liver damage by chronic carbon tetrachloride administration. Effects of the administration of melatonin or melatonin plus succinate and the combination of melatonin plus succinate plus cranberry flavonoids: the substrate-dependent respiration rate $V_{2}$ and the ADP-stimulated respiration rate $V_{3}(A)$ as well as the acceptor control ratio $\left(V_{3} / V_{2}\right)$ and the coefficient of phosphorylation ADP/O (B). Glutamate (Glu) and succinate (Suc) were used as respiratory substrates. Data, presented as a mean \pm SD, represent values at the termination of the experiment. The standard unpaired Student $t$ test was used for the comparison of the data. ${ }^{*} \mathrm{p}<0.05$ vs control non-treated animals, ${ }^{* *} \mathrm{p}<0.01$ vs control non-

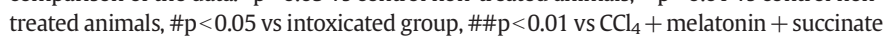
group. 
Table 1

Rat liver mitochondria thiol groups levels, mitochondrial enzymatic activities and protein content during liver damage by chronic $\mathrm{CCl}_{4}$ administration (1.6 $\mathrm{g} / \mathrm{kg}$ i.p., biweekly, 30 days). Effect of melatonin ( $10 \mathrm{mg} / \mathrm{kg}$ i.g., 30 days daily) or melatonin plus succinate (50 mg/kg i.g., 30 days daily) as well as the complex of melatonin plus succinate plus cranberry flavonoids ( $7 \mathrm{mg} / \mathrm{kg}$ i.g., 30 days daily) administration.

\begin{tabular}{|c|c|c|c|c|c|}
\hline Parameters & Control & $\mathrm{CCl}_{4}$ & $\begin{array}{l}\mathrm{CCl}_{4}+ \\
\text { melatonin }\end{array}$ & $\begin{array}{l}\mathrm{CCl}_{4}+ \\
\text { mel }+ \\
\text { succinate }\end{array}$ & $\begin{array}{l}\mathrm{CCl}_{4}+\text { mel }+ \\
\text { succinate }+ \text { flavonoids }\end{array}$ \\
\hline $\begin{array}{l}\text { TSH, } \\
\text { (nmol/mg protein) }\end{array}$ & $81.6 \pm 4.3$ & $87.8 \pm 14.7$ & $82.3 \pm 5.7$ & $87.0 \pm 3.6^{*}$ & $83.9 \pm 5.8$ \\
\hline $\begin{array}{l}\text { PSH, } \\
\text { (nmol/mg protein) }\end{array}$ & $73.8 \pm 4.0$ & $75.2 \pm 11.9$ & $72.1 \pm 4.2$ & $75.2 \pm 3.0$ & $72.8 \pm 4.8$ \\
\hline $\begin{array}{l}\text { GSH, } \\
\text { (nmol/mg protein) }\end{array}$ & $7.8 \pm 1.2$ & $12.6 \pm 3.1^{* *}$ & $10.2 \pm 1.8^{*} \#$ & $11.9 \pm 2.0^{* * *}$ & $11.1 \pm 2.4^{* *}$ \\
\hline $\begin{array}{l}\text { GSSP, } \\
\text { (nmol/mg protein) }\end{array}$ & $0.23 \pm 0.06$ & $0.30 \pm 0.06^{*}$ & $0.33 \pm 0.10^{*}$ & $0.29 \pm 0.04^{*}$ & $0.30 \pm 0.07^{*}$ \\
\hline GST, (nmol CDNB/min/ mg protein) & $40.2 \pm 5.7$ & $46.4 \pm 11.9$ & $43.2 \pm 5.9$ & $47.4 \pm 15.5$ & $45.9 \pm 5.3$ \\
\hline $\mathrm{OGDH},(\mathrm{nmol} \mathrm{NAD}+/ \mathrm{min} / \mathrm{mg}$ protein $)$ & $35.7 \pm 10.4$ & $31.4 \pm 8.2$ & $39.0 \pm 9.1$ & $33.7 \pm 10.1$ & $33.9 \pm 7.6$ \\
\hline $\mathrm{SDH},(\mathrm{nmol} \mathrm{DCPI} / \mathrm{min} / \mathrm{mg}$ protein $)$ & $51.9 \pm 6.6$ & $44.1 \pm 6.5^{*}$ & $47.5 \pm 7.7^{*}$ & $50.2 \pm 8.2^{\mathrm{b}}$ & $51.6 \pm 5.5 \#$ \\
\hline GPx (nmol GSH/min/mg protein) & $587 \pm 63$ & $336 \pm 65^{* * * *}$ & $\begin{array}{l}454 \pm 54^{* * *} \\
\text { \#\# }\end{array}$ & $356 \pm 71^{* * *}$ & $415 \pm 116^{* *}$ \\
\hline
\end{tabular}

Data, presented as a mean $\pm \mathrm{SD}$, represent values at the termination of the experiment. ${ }^{*} \mathrm{p}<0.05$ vs control non-treated animals; ${ }^{* *} \mathrm{p}<0.01$ vs control non-treated animals; ${ }^{* * * *} \mathrm{p}<0,001$ vs control non-treated animals; \#p $<0.05$ vs intoxicated group; \#\#p $<0.01$ vs intoxicated group; ${ }^{\mathrm{b}} \mathrm{p}<0,01$ vs $\mathrm{CCl}_{4}+$ melatonin group.

under intoxication was also noted (by $30 \%, \mathrm{p}<0.01$ ) and the protector administrations did not change it (Table 1 ). We observed some changes of the activities of the mitochondrial enzymes under chronic intoxication: succinate dehydrogenase (complex II) activity and glutathione peroxidase activity decreased (by $15 \%, \mathrm{P}<0.05$, and by $45 \%, \mathrm{p}<0.001$, respectively). At the same time the activities of the main enzyme of the Krebs cycle, 2-oxoglutarate dehydrogenase, and the main detoxifying enzyme, glutathione transferase, in mitochondria did not change. Melatonin or melatonin plus succinate as well as the combination of melatonin plus succinate plus cranberry flavonoids converted the values of the inhibited activity of SDH or GPx to the control (Table 1).

Under intoxication the mitochondrial membrane potential remained unchanged (data not shown). Chronic intoxication decreased the protein content in the mitochondrial fraction of rat liver tissue as well as in the liver cell cytoplasm, and the protectors had no effect on this parameter (data not shown).

Biochemical alterations during chronic intoxication. After 30 days of $\mathrm{CCl}_{4}$ treatment, the animals showed typical signs of intoxication: blood plasma level of urea increased (by $35 \%, p<0.05$ ), the markers of liver damage, plasma ALT and AST activities were elevated (by 9-fold, $\mathrm{p}<0.01$ and by 5 -fold, $\mathrm{p}<0.01$, respectively), and bilirubin level (both total and free bilirubin) in plasma increased (by 2.6- and 3.3-fold, $\mathrm{p}<0.01$, respectively) (conjugated bilirubin content did not change) (Table 2). We observed marked growth retardation of rats under chronic intoxication: the final body weight minus initial body weight decreased (by 3.3 -fold, $\mathrm{p}<0.05$ ) and the ratio of liver weight / body weight increased (by 1.6 -fold, $\mathrm{p}<0.001$ ) (Table 2). But long-term chronic intoxication did not result in alterations in the plasma NO levels. Melatonin administration daily to intoxicated animals considerably reduced both plasma aminotransferase activities and bilirubin levels (Table 2). However, melatonin was not effective in preventing increases in blood urea level or growth retardation (Table 2). Surprisingly, melatonin plus succinate was not effective in preventing the toxic liver damage. But addition of cranberry flavonoids to the melatonin plus succinate increased considerably the protective actions (Table 2).

The chronic intoxication of rats resulted in pronounced rises in the cellular reduced glutathione content (more than twice, $\mathrm{p}<0.0001$ ) and, consequently, in the total cellular sulfhydryl group contents (1.3-fold, $p<0.01$ ) in the postmitochondrial fraction of liver cells (in accordance with mitochondrial thiol group levels change), while the level of protein sulfhydryl groups in liver tissue did not change (Table 3). The content of mixed protein-glutathione disulfides in the liver cellular postmitochodrial fraction raised as a result of chronic intoxication (1.6-fold, $p<0.01$ ) and the activity of the antioxidant enzyme, catalase, decreased (1.6-fold, $\mathrm{p}<0.001)$. The hepatic TBARS level considerably increased $(1.9$-fold, $\mathrm{p}<0.001)$ under intoxication in accordance with many other observations (Table 3 ).

Melatonin administration during 30-days to intoxicated rats partially prevented the rises in both cellular and mitochondrial reduced

Table 2

Blood plasma urea, nitric oxide and bilirubin levels, ALT and AST activities, and animal body and liver weights in normal and chronically $\mathrm{CCl}_{4}$-treated rats (1.6 g/kg i.p., biweekly, 30 days). Effect of melatonin ( $10 \mathrm{mg} / \mathrm{kg}$ i.g., 30 days daily) or melatonin plus succinate ( $50 \mathrm{mg} / \mathrm{kg}$ i.g., 30 days daily) as well as the complex of melatonin plus succinate plus cranberry flavonoids (7 mg/kg i.g., 30 days daily) administration.

\begin{tabular}{|c|c|c|c|c|c|}
\hline Parameter & control & $\mathrm{CCl}_{4}$ & $\begin{array}{l}\mathrm{CCl}_{4}+ \\
\text { melatonin }\end{array}$ & $\begin{array}{l}\mathrm{CCl}_{4}+ \\
\text { mel }+ \\
\text { succinate }\end{array}$ & $\begin{array}{l}\mathrm{CCl}_{4}+\text { mel }+ \\
\text { succinate }+ \text { flavonoids }\end{array}$ \\
\hline Blood urea, $(\mathrm{mmol} / \mathrm{l})$ & $5.7 \pm 0.9$ & $7.6 \pm 0.6^{* * *}$ & $7.5 \pm 1.1^{* *}$ & $7.6 \pm 0.7^{* * *}$ & $7.9 \pm 0.6^{* * *}$ \\
\hline $\mathrm{NO},(\mu \mathrm{mol} / \mathrm{l})$ & $30.0 \pm 6.4$ & $26.5 \pm 3.6$ & $29.2 \pm 8.1^{c}$ & $23.1 \pm 4.6^{*}$ & $27.9 \pm 4.2^{\mathrm{c}}$ \\
\hline ALT, $\mu \mathrm{kat} / \mathrm{l}$ & $1.03 \pm 0.24$ & $9.39 \pm 1.99^{* * *}$ & 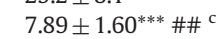 & $10.79 \pm 1.57^{* * *}$ & $7.21 \pm 2.03^{* * *} \#^{\mathrm{c}}$ \\
\hline AST, $\mu \mathrm{kat} / \mathrm{l}$ & $0.94 \pm 0.30$ & $4.61 \pm 1.41^{* * * *}$ & $2.49 \pm 0.21^{* * *} \#^{\mathrm{c}}$ & $6.47 \pm 1.43^{* * *} \#$ & $1.41 \pm 0.24^{* *} \# \#^{\text {c b }}$ \\
\hline Total bilirubin, $(\mu \mathrm{mol} / \mathrm{l})$ & $10.2 \pm 3.7$ & $26.1 \pm 10.5^{* *}$ & $14.0 \pm 4.6^{*} \#^{c}$ & $26.8 \pm 10.1^{* *}$ & $10.4 \pm 6.5 \#^{c}$ \\
\hline Free bilirubin, $(\mu \mathrm{mol} / \mathrm{l})$ & $6.8 \pm 3.5$ & $22.3 \pm 10.5^{* *}$ & $11.9 \pm 5.2 * \#$ & $21.4 \pm 10.0^{*}$ & $6.9 \pm 3.2 \#^{c}$ \\
\hline Conjugated bilirubin, $(\mu \mathrm{mol} / \mathrm{l})$ & $3.9 \pm 2.5$ & $4,4 \pm 2,4$ & $3.1 \pm 1,8$ & $6.2 \pm 2.4$ & $4,7 \pm 2.8$ \\
\hline Body weight (final-initial), (g) & 49 & $15^{*}$ & $9^{*}+1,0$ & $2^{*}$ & $6^{*}+1,0$ \\
\hline Liver/Body weight, $(\mathrm{g} / \mathrm{g})$ & $0.031 \pm 0.003$ & $0.049 \pm 0.006^{* * *}$ & $0.045 \pm 0.005^{* * *}$ & $0.046 \pm 0.005^{* * *}$ & $0.044 \pm 0.009^{*}$ \\
\hline
\end{tabular}

Data, presented as a mean $\pm \mathrm{SD}$, represent values at the termination of the experiment. ${ }^{*} \mathrm{p}<0.05$ vs control non-treated animals; ${ }^{* *} \mathrm{p}<0.01 \mathrm{vs}$ control non-treated animals; \#p $<0.05$ vs intoxicated group; \#\#p<0.01 vs intoxicated group; ${ }^{\mathrm{b}} \mathrm{p}<0,01$ vs $\mathrm{CCl}_{4}+$ melatonin group; ${ }^{\mathrm{c}} \mathrm{p}<0.01$ vs $\mathrm{CCl}_{4}+$ melatonin + succinate group. 
Table 3

Rat liver cell thiol groups, lipid peroxidation products levels, catalase activity and protein content during liver damage by chronic $\mathrm{CCl}_{4}$ administration (1.6 g/ $\mathrm{kg}$ i.p., biweekly, 30 days). Effect of melatonin ( $10 \mathrm{mg} / \mathrm{kg}$ i.g., 30 days daily) or melatonin plus succinate ( $50 \mathrm{mg} / \mathrm{kg}$ i.g., 30 days daily) as well as the complex of melatonin plus succinate plus cranberry flavonoids ( $7 \mathrm{mg} / \mathrm{kg}$ i.g., 30 days daily) administration.

\begin{tabular}{|c|c|c|c|c|c|}
\hline Parameters & control & $\mathrm{CCl}_{4}$ & $\begin{array}{l}\mathrm{CCl}_{4}+ \\
\text { melatonin }\end{array}$ & $\begin{array}{l}\mathrm{CCl}_{4}+ \\
\text { mel }+ \\
\text { succinate }\end{array}$ & $\begin{array}{l}\mathrm{CCl}_{4}+\text { mel }+ \\
\text { succinate }+ \text { flavonoids }\end{array}$ \\
\hline TSH, (nmol/mg protein) & $114.0 \pm 10.9$ & $151.0 \pm 24.9^{* *}$ & $136.1 \pm 21.1^{*}$ & $147.2 \pm 17.6^{* * *}$ & $146.8 \pm 18.5^{* * *}$ \\
\hline $\mathrm{PSH},(\mathrm{nmol} / \mathrm{mg}$ protein) & $83.9 \pm 5.7$ & $80.4 \pm 8.2$ & $78.9 \pm 8.7$ & $78.4 \pm 9.9$ & $80.3 \pm 10.1$ \\
\hline GSH, (nmol/mg protein) & $29.9 \pm 8.1$ & $70.6 \pm 19.7^{* * *}$ & $57.2 \pm 14.6^{* * *}$ & $68.8 \pm 10.8^{* * *}$ & $66.5 \pm 15.1^{* * *}$ \\
\hline GSSP, (nmol/mg protein) & $0.45 \pm 0.14$ & $0.73 \pm 0.21^{* *}$ & $0.56 \pm 0.04 \#^{c}$ & $0.71 \pm 0.15^{* *}$ & $0.73 \pm 0.15^{* * \mathrm{~b}}$ \\
\hline TBARS, (nmol/mg protein) & $0.2 \pm 0.03$ & $0.37 \pm 0.07^{* * *}$ & $0.28 \pm 0.04^{* * *} \#^{c}$ & $0.36 \pm 0.08^{* * *}$ & $0.21 \pm 0.05 \# \# \#$ a c \\
\hline Catalase, ( $\mu \mathrm{mol} \mathrm{H}_{2} \mathrm{O}_{2} / \mathrm{min} / \mathrm{mg}$ protein) & $365.3 \pm 35.8$ & $139.5 \pm 56.1^{* * *}$ & $170.3 \pm 34.0^{* * *}$ & $135.7 \pm 51.3^{* * *}$ & $180.3 \pm 44.6^{* * *}$ \\
\hline
\end{tabular}

Data, presented as a mean \pm SD, represent values at the termination of the experiment. ${ }^{*} \mathrm{p}<0.05$ vs control non-treated animals; ${ }^{* *} \mathrm{p}<0.01$ vs control non-treated animals; ${ }^{* * *}$ $\mathrm{p}<0.001$ vs control non-treated animals; \#p $<0.05$ vs intoxicated group; \#\#p $<0.01$ vs intoxicated group; ${ }^{\mathrm{a}} \mathrm{p}<0,05$ vs $\mathrm{CCl}_{4}+$ melatonin group; ${ }^{\mathrm{b}} \mathrm{p}<0,01$ vs $\mathrm{CCl}{ }_{4}+$ melatonin group; ${ }^{\mathrm{p}}<0.01 \mathrm{vs} \mathrm{CCl}_{4}+$ melatonin + succinate group.
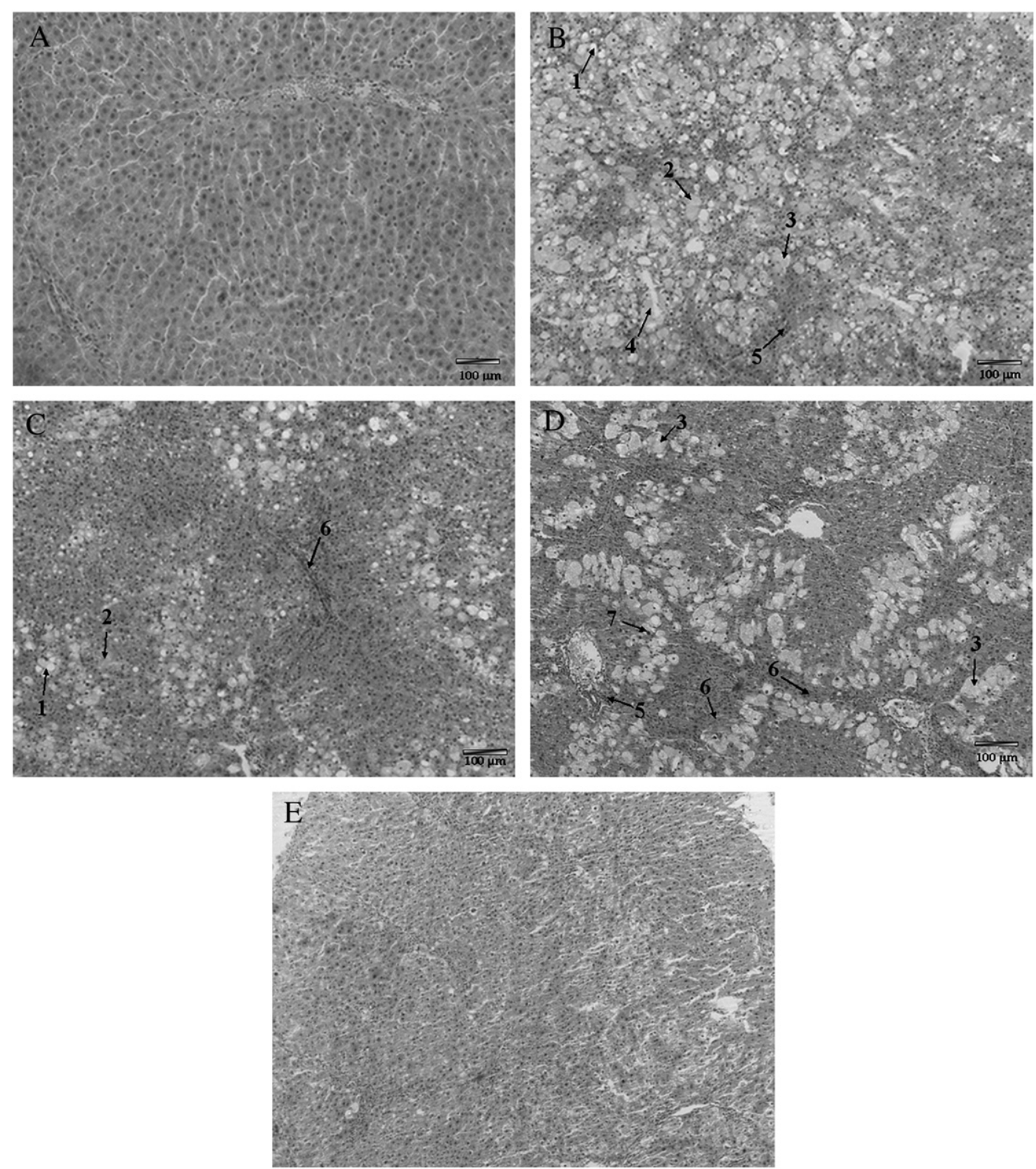

Fig. 2. Representative histological sections from liver tissue from control animals (A), intoxicated animals (B) and intoxicated animals treated by melatonin (C), by melatonin plus succinate (D), by combination of melatonin plus succinate plus cranberry flavonoids (E). H\&E, x 210; scale bar, $100 \mu \mathrm{m}$. Signs of morphological transformations: 1 , fatty dystrophy; 2 , hydropic dystrophy; 3 , ballooning dystrophy; 4 , site of hepatocyte necrobiosis and necrosis; 5 , lymphocyte infiltration; 6 , sclerosis of portal areas; 7 , enlarged and hyperchromic nuclei. 

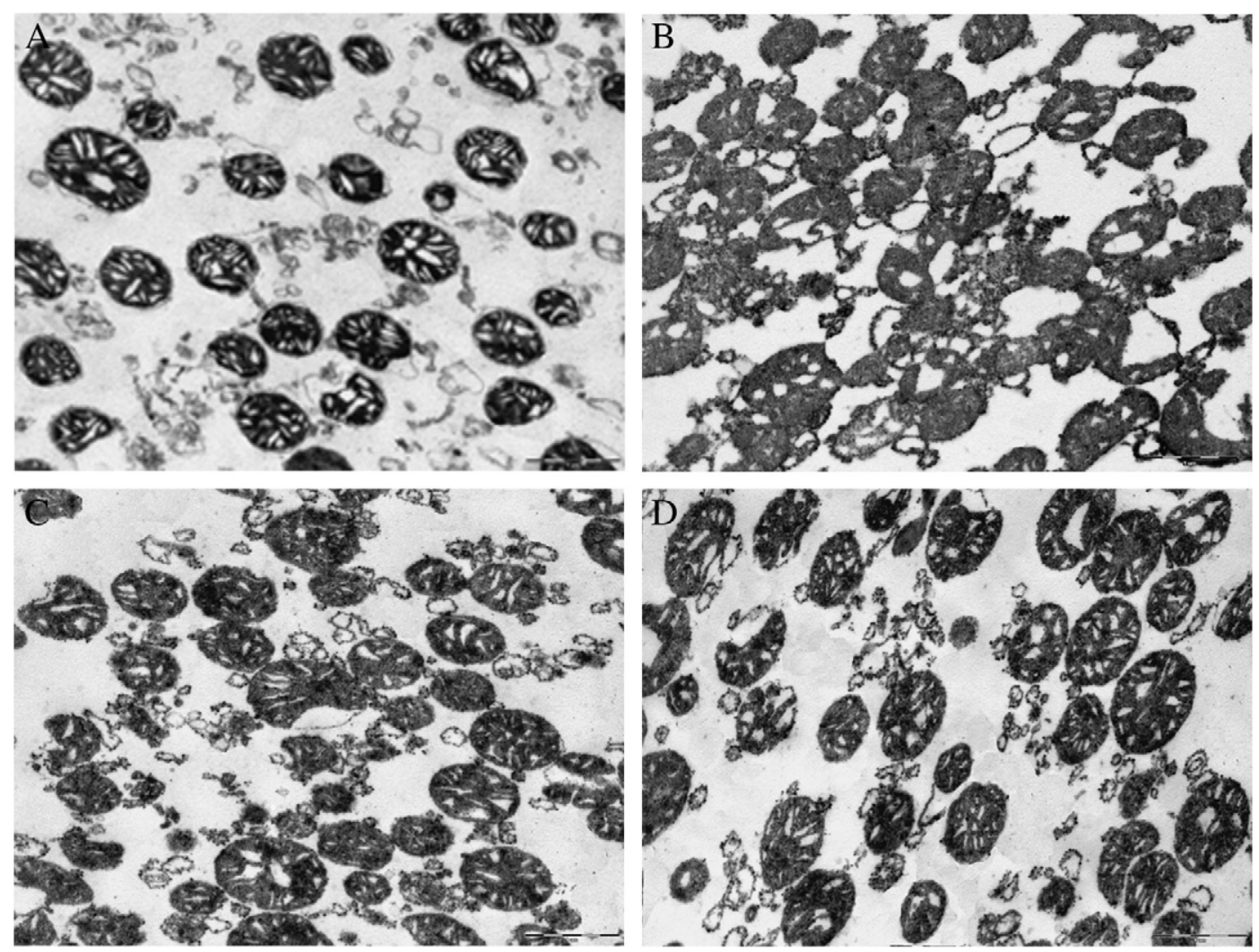

Fig. 3. Rat liver mitochondria ultrastructure: control animals (A), intoxicated animals (B) and intoxicated animals treated by melatonin (C) and by the combination of melatonin plus succinate plus cranberry flavonoids (D); x20,000; scale bar, $1 \mu \mathrm{m}$.

glutathione and total sulfhydryl group content in liver, inhibition of cytoplasm catalase as well as normalized the liver tissue TBARS level (Table 3). Combined administration of melatonin and succinate did not increase the effectiveness of the therapy. At the same time, treatment of the animals with a combination of melatonin plus succinate plus cranberry flavonoids was more effective in comparison with melatonin alone.

Morphological transformations of liver cells and mitochondria during intoxication

Histopathological analysis of the rat liver. Histologically, control rats showed normal hepatic architecture (Fig. 2A). In accordance with numerous observations, chronic $\mathrm{CCl}_{4}$ intoxication caused substantial morphological changes in the rat liver (Fig. 2B). The histological examination demonstrated disruption of hepatic lobular structure including a high degree of fatty (mainly with small-sized lipid droplets) and hydropic dystrophies that transformed to ballooning dystrophy. Many cell nuclei were enlarged. Extensive sites of hepatocyte necrobiosis, necrosis and apoptosis were observed, particularly in the second and the

Table 4

Blood plasma AST and ALT activities, nitric oxide level in normal and acute $\mathrm{CCl}_{4}$-treated rats $(0.8 \mathrm{~g} / \mathrm{kg}$ i.g., 24 hours). Effects of melatonin ( $10 \mathrm{mg} / \mathrm{kg}$ i.p. $\times 3$ 3) administration.

\begin{tabular}{lllll}
\hline Parameters & control & $\mathrm{CCl}_{4}$ & $\begin{array}{l}\mathrm{CCl}_{4}+ \\
\text { melatonin }\end{array}$ & $\begin{array}{l}\text { control }+ \\
\text { melatonin }\end{array}$ \\
\hline AST, $(\mu \mathrm{kat} / \mathrm{l})$ & $0.88 \pm 0.09$ & $1.33 \pm 0.20^{* * *}$ & $1.34 \pm 0.17^{* * *}$ & $0,87 \pm 0,11$ \\
$\mathrm{ALT},(\mu \mathrm{kat} / \mathrm{l})$ & $0.89 \pm 0.15$ & $1.96 \pm 0.05^{* * *}$ & $1.95 \pm 0.09^{* * *}$ & $0,83 \pm 0,17$ \\
$\mathrm{NO},(\mu \mathrm{mol} / \mathrm{l})$ & $28.2 \pm 6.6$ & $43.8 \pm 14.1^{*}$ & $32.2 \pm 15.0$ & $40.1 \pm 15.3$ \\
\hline
\end{tabular}

Data, presented as a mean $\pm S D$, represent values at the termination of the experiment; ${ }^{* * *} \mathrm{p}<0.001$ vs control non-treated animals. third hepatic lobes. Dystrophic and necrobiotic changes in hepatocytes were less pronounced in the first lobe. Both intralobular and periportal lymphocyte infiltration and sclerosis of portal areas were revealed everywhere. In some cases, there was hepatocyte sequestration. Substantial hepatocyte destructive changes point to highly toxic chronic hepatitis with formation of septal cirrhosis.

Melatonin administration under liver intoxication dramatically reduced the liver lobular and ballooning destructive changes (Fig. 2C). Hyperplastic processes in undamaged hepatocytes enhanced under melatonin treatment: many hepatocyte nuclei were enlarged and hyperchromic (Fig. 2C). After combined treatment of intoxicated rats with melatonin and succinate, hepatic structure changes were similar to those seen in rats that received melatonin only (Fig. 2D). Intoxicated rats treated with the combination of melatonin plus succinate plus cranberry flavonoids exhibited slight hepatocyte destructive changes, including slight fatty and hydropic dystrophy, lymphocyte infiltration and sclerosis to a lesser extent in comparison with the other groups (Fig. 2E).

Rat liver mitochondrial ultrastructure. The mitochondrial ultrastructure was examined by electron microscopy. Basically, the isolated mitochondria from control rat livers had an oval shape and were characterized by a condensed matrix and slightly expanded intracristae spaces (Fig. 3A).

Mitochondria isolated from the livers of chronically $\mathrm{CCl}_{4}$-treated rats displayed substantial irreversible impairments, including a more condensed matrix, reduction in the number of cristae in comparison with those of control rat liver (Fig. 3B). About $70 \%$ of mitochondria had a substantial enlargement of intracristae space with vacuole formations of different size up to detachment of the inner mitochondria membrane. Some mitochondria were disruptured by outer membrane rupture due to large vacuole formation (Fig. 3B). In the mitochondrial suspension from intoxicated animals, we could observe mitochondria 
Table 5

Rat liver mitochondrial glutathione level, mitochondrial enzymatic activity and membrane potential during liver damage by acute $\mathrm{CCl}_{4}$ administration ( $0.8 \mathrm{~g} / \mathrm{kg}$ i.g., 24 hours). Effects of melatonin (10 mg/kg i.p. x 3) administration.

\begin{tabular}{|c|c|c|c|c|}
\hline Parameters & control & $\mathrm{CCl}_{4}$ & $\underset{\text { melatonin }}{\mathrm{CCl}_{4}+}$ & $\begin{array}{l}\text { control }+ \\
\text { melatonin }\end{array}$ \\
\hline GSH, (nmol/mg protein) & $8.6 \pm 0.9$ & $9.0 \pm 2.0$ & $10.1 \pm 1.4^{*}$ & $8.0 \pm 1.0$ \\
\hline GSSP (nmol/mg protein) & $0.21 \pm 0.09$ & $0.20 \pm 0.09$ & $0.23 \pm 0.07$ & $0.28 \pm 0.07$ \\
\hline $\mathrm{SDH}$, (nmol DCPI/min/mg protein) & $43.6 \pm 2.9$ & $32.5 \pm 5.5^{* * *}$ & $36.6 \pm 5.5^{* *}$ & $42.8 \pm 4.7$ \\
\hline $\mathrm{GPx}(\mathrm{nmol} \mathrm{GSH} / \mathrm{min} / \mathrm{mg}$ protein) & $745 \pm 290$ & $730 \pm 205$ & $805 \pm 180$ & $770 \pm 235$ \\
\hline Membrane potential, $(\mathrm{mV})$, glutamate as a substrate $(5 \mathrm{mM})$ & $-146.9 \pm 11.5$ & $-160.2 \pm 19.3$ & $-165.2 \pm 9.2^{* *}$ & $-149.8 \pm 13.5$ \\
\hline Membrane potential, (mV), succinate as a substrate ( $5 \mathrm{mM})$ & $-171.8 \pm 8.0$ & $-186.3 \pm 7.3^{* *}$ & $-183.1 \pm 6.7^{*}$ & $-176.1 \pm 3.5$ \\
\hline
\end{tabular}

Data, presented as a mean $\pm \mathrm{SD}$, represent values at the termination of the experiment. ${ }^{*} \mathrm{p}<0.05$ vs control non-treated animals; ${ }^{* *} \mathrm{p}<0.01$ vs control non-treated animals; ${ }^{* * *} \mathrm{p}<0.001$ vs control non-treated animals.

self-association. Long-term melatonin administration to intoxicated animals appreciably prevented mitochondrial damage. Mitochondria became less destroyed (Fig. 3C). About 30\% of the mitochondria demonstrated irreversible destructive changes: detachment of the inner mitochondria membrane with vesicle formation or cristae reduction (Fig. 3C). Virtually all the mitochondria had an oval shape, but possessed enlarged intracristae spaces with vacuole formations and showed heterogeneity of matrix density.

After simultaneous administration of melatonin, succinate and cranberry flavonoids to intoxicated rats, destructive changes in mitochondria became less marked (Fig. 3D) in comparison with those in mitochondria isolated from intoxicated rats treated either with melatonin or melatonin plus succinate.
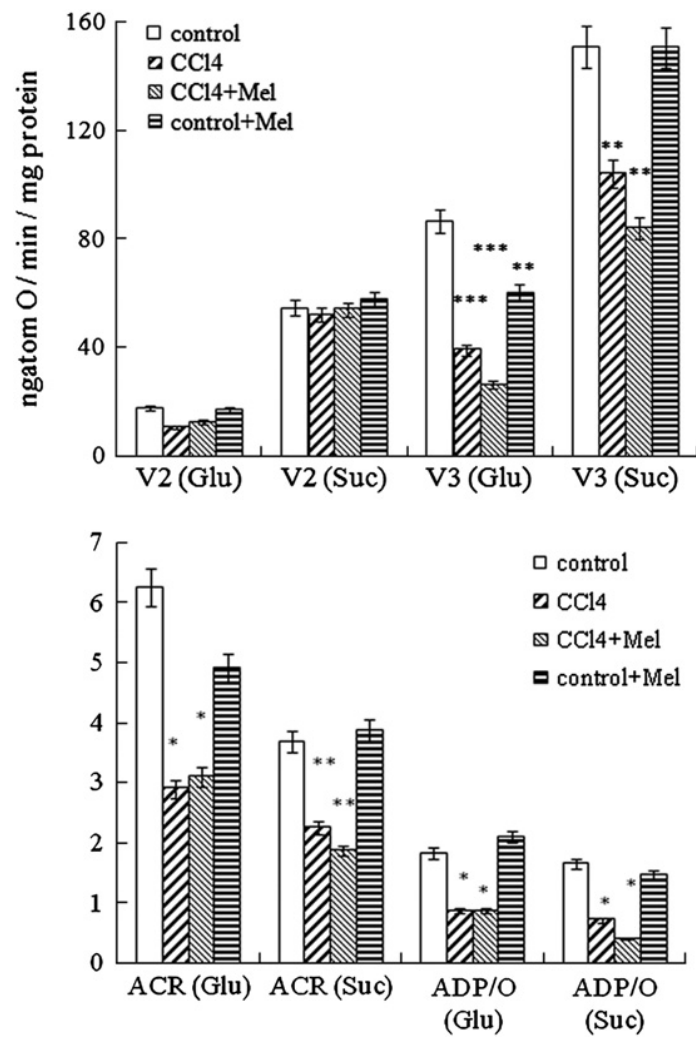

Fig. 4. Parameters of oxidative phosphorylation processes in rat liver mitochondria under liver damage by acute carbon tetrachloride administration $(0.8 \mathrm{~g} / \mathrm{kg}$, i.g., 24 hours). Effects of melatonin $(10 \mathrm{mg} / \mathrm{kg}$, i.p. $x$ 3) administration: the substratedependent respiration rate $V_{2}$ and the ADP-stimulated respiration rate $V_{3}(A)$ as well as the acceptor control ratio $\left(V_{3} / V_{2}\right)$ and the coefficient of phosphorylation ADP/O (B). Glutamate (Glu) and succinate (Suc) were used as respiratory substrates. Data, presented as a mean $\pm S D$, represent values at the termination of the experiment. The standard unpaired Student $t$ test was used for the comparison of the data. ${ }^{*} \mathrm{p}<0.05$ vs control non-treated animals, ${ }^{* *} \mathrm{p}<0.01$ vs control non-treated animals, *** $\mathrm{p}<0.001$ vs control non-treated animals.

\section{Mitochondrial effects of acute $\mathrm{CCl}_{4}$ intoxication and melatonin administration}

The single (acute) administration of the carbon tetrachloride at a dose of $0.8 \mathrm{~g} / \mathrm{kg}$ b.w. to rats at 24 hours had effects that differed from those of the chronic $\mathrm{CCl}_{4}$ administration. The acute $\mathrm{CCl}_{4}$ administration was accompanied by damage to hepatocyte plasma membrane, resulting in a marked elevation of hepatocytic enzymes ALT (1.2-fold, $\mathrm{p}<0.001)$ and AST (1.5-fold, $\mathrm{p}<0.001$ ) in plasma (Table 4). We observed an increase of plasma nitric oxide level (1.55-fold, $\mathrm{p}<0.05)$. Short-term treatment of rats by melatonin did not prevent toxic liver impairment but decreased NO production.

The acute intoxication did not change the levels of mitochondrial reduced glutathione and mixed protein-glutathione disulfides (Table 5). Only the liver mitochondria of rats treated with $\mathrm{CCl}_{4}+$ melatonin showed a slight rise of the GSH levels (1.2-fold, $\mathrm{p}<0.05$ in comparison with control animals). The activity of mitochondrial succinate dehydrogenase (but not glutathione peroxidase) decreased (1.25-fold, $\mathrm{p}<0.001)$ and melatonin administration did not prevent these changes (Table 5).

Acute $\mathrm{CCl}_{4}$ intoxication resulted in a considerable impairment of mitochondrial respiratory parameters in the liver, the ADP-stimulated respiration rate $\mathrm{V}_{3}$, acceptor control ratio, respiratory control ratio and phosphorylation coefficient ADP/O decreased (1.5-1.55-fold, $\mathrm{p}<0.05$ ) with glutamate as respiratory substrate, whereas with succinate as respiratory substrate, the same parameters decreased by 1.3 -fold $(\mathrm{p}<0.01)$, 1.4 -fold ( $\mathrm{p}<0.01), 1.5$-fold $(\mathrm{p}<0.01)$ and 1.55 -fold $(\mathrm{p}<0.05)$, respectively (Fig. 4). The short-term administration of melatonin did not substantially change the respiratory parameters of mitochondria in both control and intoxicated animals. We observed enhancement of the mitochondrial membrane potential under acute intoxication, and melatonin administration did not prevent this effect (Table 5).

\section{Discussion}

In the present work, we compared the mitochondrial effects of acute (single injection) and chronic (30 days) $\mathrm{CCl}_{4}$-induced intoxication and evaluated the hepatoprotective potential of some antioxidants.

There are a lot of data on the mitochondrial effects of intoxication and the role of mitochondrial impairments in the pathogenesis of toxic tissue damage. Krahenbuhl et al. have shown that hepatic mitochondrial function is impaired in rats with $\mathrm{CCl}_{4}$-induced cirrhosis due to both reduced mitochondrial volume per liver and impaired metabolism of the remaining mitochondria (Krähenbühl et al., 2000). Dissipation of mitochondrial membrane potential (14.8\%) and intramitochondrial $\mathrm{Ca}^{2+}$ overload (2.1-fold) were observed in liver cells of $\mathrm{CCl}_{4}$-insulted mice (Chiu et al., 2007). $\mathrm{CCl}_{4}$-hepatotoxicity in mice caused an increase in the sensitivity of mitochondria to $\mathrm{Ca}^{2+}$-stimulated permeability transition which was associated with the rise in mitochondrial $\mathrm{Ca}^{2+}$-content, the extent of reactive oxygen species production and cytochrome $c$ release (Chiu et al., 2007). It has recently been shown that specific protection against hepatocyte mitochondrial dysfunction plays a preventive role in early stages of the fibrotic processes (Mitchell et al., 2009). The mechanisms of liver protection 
during intoxication by different agents might be related to regulation of mitochondrial functions, inhibiting the process of mitochondrial permeability transition and improvement of mitochondrial biogenesis (Tang et al., 2005; Gao et al., 2006).

In the present study, the pathomorphological analysis demonstrated that long-term $\mathrm{CCl}_{4}$ - intoxication caused severe chronic hepatitis and septal cirrhosis formation. These liver structure impairments were associated with considerable irreversible mitochondria damages, including outer membrane destruction, large intramitochondria vacuole formation and cristae reduction. This is in line with the report by Bezborodkina et al. (2008) who showed that in spite of the increase in the volume density of mitochondria in cells of the cirrhotic liver (by 28\%), the concentration of internal mitochondrial membranes and the total length of the internal membrane were reduced.

Earlier our electron microscopic investigation of the hepatic samples of rats after acute high dose $\mathrm{CCl}_{4}$ - intoxication $(4.0 \mathrm{~g} / \mathrm{kg})$ indicated substantial ultrastructural changes, which were more marked for hepatocytes than for the microvascular bed (Zavodnik et al., 2005). Mitochondria displayed considerable changes, including a highly variable structure with hypertrophy, swelling and clarification of their matrix, reduction in the number of cristae. In our previous study, short-term melatonin administration showed a beneficial effect, decreasing dystrophic cell changes, inflammation processes and lipid inclusions (Zavodnik et al., 2005).

We found that acute intoxication of rats with a low dose of the toxic agent $(0.8 \mathrm{~g} / \mathrm{kg})$ resulted in considerable impairments of respiratory function of rat liver mitochondria without alterations in the GSH level. Short-term melatonin administration neither influenced considerably the respiratory parameters of liver mitochondria of intoxicated and control animals, nor prevented hepatolysis under acute intoxication. In our earlier experiment, the high-dose acute intoxication $(4.0 \mathrm{~g} / \mathrm{kg})$ led to complete uncoupling of respiration and phosphorylation and the loss of respiration control in rat liver mitochondria (Maksimchik et al., 2010). In the case of high-dose and low-dose acute intoxication, but not under chronic intoxication, the level of plasma nitric oxide increased and melatonin administration decreased NO level under intoxication.

We demonstrated that the liver damage (ALT or AST plasma activities and bilirubin content) was much more severe under long-term intoxication than after the low dose single $\mathrm{CCl}_{4}$ injection. However, after 30 days of chronic $\mathrm{CCl}_{4}$ intoxication, the functional parameters of mitochondria were similar to the control values, despite the considerable changes in redox-balance of mitochondria as a result of chronic intoxication (rise of the mitochondrial levels of GSH, or GSSP, inhibition of mitochondrial glutathione peroxidase or succinate dehydrogenase) and mitochondrial morphology damage. On the other hand, it was found that the activities of complexes I and IV of the mitochondrial respiratory chain were significantly decreased in wild-type mice rather than in Bcl-2 transgenic mice after chronic $\mathrm{CCl}_{4}$ administration (Mitchell et al., 2009). We observed a compensation of the functional activity of mitochondria after long-term intoxication. The elevated content of GSH in mitochondria may serve as a factor of mitochondrial adaptation to constant effect of the toxic agent. To interpret this finding, we turned to several reports that demonstrated that the induction of GSH synthesis due to elevated expression of $\gamma$-glutamylcysteine synthetase, and, consequently, enhancing the cellular defense potential are one of the common adaptive responses to GSH depleting agents or oxidative stress (Shi et al., 1994; Liu et al., 1996; Moellering et al., 2002; Kurozumi et al., 2005). The increase in hepatic GSH, that occurs coincident with overt hepatotoxicity, was observed after $\alpha$-naphthylisothiocyanate administration to rats (Dahm et al., 1991). On the opposite, a considerable decrease of glutathione levels was demonstrated in liver tissue of mice after 8 weeks of $\mathrm{CCl}_{4}$ intoxication with a subsequent activation of glutathione peroxidase and glutathione reductase (Hsiao et al., 2001). We found that the activity of mitochondrial glutathione peroxidase consuming GSH decreased under chronic intoxication. The activity of catalase in the hepatocyte cytoplasm considerably decreased, as well as the TBARS level in rat liver tissue increased after $\mathrm{CCl}_{4}$ administration as a result of repeated oxidative stress.

Beneficial effects of melatonin, a direct and indirect antioxidant (Rodriguez et al., 2004; Reiter et al., 2007), during toxic liver damage were observed in numerous studies (Daniels et al., 1995; Kus et al., 2005; Ohta et al., 2004; Galano et al., 2011). Melatonin administration during acute $\mathrm{CCl}_{4}$-induced rat intoxication dose-dependently reduced morphological liver damage (Kus et al., 2005) and attenuated the reduction in hepatic superoxide dismutase, catalase and glutathione reductase activities (Ohta et al., 2004). Mitochondrial effects of melatonin may be related to the ability of melatonin to inhibit strongly the mitochondrial permeability transition pores and cytochrome c release (Andrabi et al., 2004; Jou et al., 2007). Being an antioxidant and inhibitor of mitochondrial permeability transition pore, melatonin may provide a beneficial therapeutic treatment of toxic liver damage.

In our experiment, the long-term melatonin administration during chronic intoxication demonstrated pronounced hepatoprotective properties, decreasing the intensity of necrotic and inflammatory processes, and improving the hepatocyte antioxidant balance, thus preventing TBARS accumulation and contributing to enhancement of regenerative processes in liver tissue, as well as preventing mitochondrial membrane impairments. Melatonin administration decreased the level of oxidative stress and, correspondingly, prevented a considerable elevation of cellular and mitochondrial glutathione contents.

Histopathological examination confirmed the hepatoprotective effects of melatonin and its combination with succinate and cranberry flavonoids. Earlier Domitrovic and Jakovac (2010) demonstrated dose -dependent hepatoprotective effects of flavonoids on carbon tetrachloride-induced acute liver damage in rats due to promoting extracellular matrix degradation and down-regulation of fibrogenic stimuli. Also, we have previously shown that succinate administration to diabetic animals improved the mitochondrial physiology: increased the respiration rate of isolated rat liver mitochondria and prevented a loss of respiratory control, rising the acceptor control ratio value (Zavodnik et al., 2011).

The complex of melatonin plus succinate plus cranberry flavonoids was much more effective in preventing chronic liver damage. A reasonable explanation for such an effect of this combination might be found in the study by Jacobs et al. (2010). The authors showed that the powerful antioxidant semi-synthetic flavonoid 7-mono-O-( $\beta$-hydroxyethyl)-rutoside oxidized in blood plasma to a highly reactive product which could be regenerated by other antioxidant, ascorbate (Jacobs et al., 2010). In our experiment, melatonin can act as such an antioxidant and may participate in recycling other oxidized protectors (flavonoids).

In conclusion, multiple events, including considerable mitochondrial ultrastructure impairments, inhibition of mitochondrial enzymes (enzymes of electron-transport chain and antioxidative defense), protein modification (GSSP formation) and lipid peroxidation due to free radical attack contribute to development of liver damage and dysfunction during chronic and acute $\mathrm{CCl}_{4}$ intoxication. Acute intoxication resulted in pronounced impairments of mitochondrial respiratory parameters. Despite numerous biochemical and morphological signs of intoxication after 30 days of toxic agent administration, an adaptation of mitochondrial respiratory parameters was observed. Longterm melatonin administration prevented markedly mitochondrial membrane damage and enhanced regenerative processes in the liver. The hepatoprotective effect of melatonin is due to antioxidant, membranestabilizing and anti-inflammatory properties. The synergistic action of melatonin, succinate and plant polyphenols may be useful for clinical application.

\section{Conflict of interest statement}

The authors declare that there is no conflict of interest. 


\section{Acknowledgments}

This study was partially supported by grant B11PL-005 from the Belarussian Foundation for Fundamental Research. We are grateful to Ms. Lyudmila Kiryukhina for the help in the preparation of the manuscript.

\section{References}

Andrabi, S.A., Sayeed, I., Siemen, D., Wolf, G., Horn, T.F., 2004. Direct inhibition of the mitochondrial permeability transition pore: a possible mechanism responsible for anti-apoptotic effects of melatonin. FASEB J. 18, 869-871.

Bezborodkina, N.N., Okovityy, S.V., Kudriavtseva, M.V., Kirik, O.V., Zarubina, I.V., Kudriavtsev, B.N., 2008. Morphometry of hepatocyte mitochondrial apparatus in normal and cirrhotic rat liver. Tsitologiia 50, 228-236.

Chiu, P.Y., Leung, H.Y., Siu, A.H., Poon, M.K., Ko, K.M., 2007. Schisandrin B decreases the sensitivity of mitochondria to calcium ion-induced permeability transition and protects against carbon tetrachloride toxicity in mouse livers. Biol. Pharm. Bull. 30, 1108-1112.

Dahm, L., Bailie, M.B., Roth, R.A., 1991. Relationship between $\alpha$-naphthylisocyanate administration and elevations in hepatic non-protein sulfhydryl content. Biochem. Pharmacol. 42, 1189-1194.

Daniels, W.M., Reiter, R.J., Melchiorry, D., Sewerynek, E., Pablos, M.I., Ortiz, G.G., 1995. Melatonin counteracts lipid peroxidation induced by carbone tetrachloride but does not restore glucose-6-phosphatase activity. J. Pineal Res. 19, 1-6.

Domitrovic, R., Jakovac, H., 2010. Antifibrotic activity of anthocyanidin delphinidin in carbon tetrachloride-induced hepatotoxicity in mice. Toxicology 272, 1-10.

Ellman, G., 1959. Tissue sulfhydryl groups. Arch. Biochem. Biophys. 82, 70-77.

Gabriel, B.L., 1982. Biological electron microscopy. Van Nostrand Reinhold, New York.

Galano, A., Tan, D.X., Reiter, R.J., 2011. Melatonin as a natural ally against oxidative stress: a physicochemical examination. J. Pineal Res. 51, 1-16.

Gao, J., Chen, J., Tang, X., Pan, L., Fang, F., Xu, L., Zhao, X., Xu, Q., 2006. Mechanism underlying protection of Asiatic acid against hepatotoxicity in mice. J. Pharm. Pharmacol. $58,227-233$.

Green, L.C., Wagner, D.A., Glogowski, J., Skipper, P.L., Wishnok, J.S., Tannenbaum, S.R., 1982. Analysis of nitrate, nitrite, and $\left[{ }^{15} \mathrm{~N}\right]$ nitrate in biological fluids. Anal. Biochem. 126, 131-138.

Habig, W.H., Pabst, M.J., Jacoby, W.B., 1974. Glutathione-S-transferases. The first enzymatic step in mercapturic acid formation. J. Biol. Chem. 249, 7130-7139.

Hsiao, G., Lin, Y.-H., Lin, C.-H., Chou, D.-S., Lin, W.-C., Sheu, J.-R., 2001. The protective effects of PMC against chronic carbon tetrachloride-induced hepatotoxicity in vivo. Biol. Pharm. Bull. 24, 1271-1276.

Jacobs, H., Moalin, M., Bast, A., van der Vijgh, W.J.F., Haenen, G.R.M.M., 2010. An essential difference between the flavonoids monoHER and quercetin in their interplay with the endogenous antioxidant network. PLoS One 5 (11), e13880, http://dx.doi.org/ 10.1371/journal.pone.0013880.

Jaeschke, H., Bajt, M.L., 2006. Intracellular signaling mechanisms of acetaminophen-induced liver cell death. Toxicol. Sci. 89, 31-41.

Johnson, D., Lardy, H.A., 1967. Isolation of liver or kidney mitochondria. Methods Enzymol. $10,94-101$.

Jou, M.J., Peng, T.I., Yu, P.Z., Jou, S.D., Reiter, R.J., Chen, I.Y., Wu, H.Y., Chen, C.C., Hsu, L.F., 2007. Melatonin protects against common deletion of mitochondrial DNA-augmented mitochondrial oxidative stress and apoptosis. J. Pineal Res. 43, 389-403.

Ju, C., Reilly, T.P., Bourdi, M., Radonovich, M.F., Brady, J.N., George, J.W., Pohl, L.R., 2002. Protective role of Kupffer cells in acetaminophen-induced hepatic injury in mice. Chem. Res. Toxicol. 15, 1504-1513.

Krähenbühl, L., Ledermann, M., Lang, C., Krähenbühl, S., 2000. Relationship between hepatic mitochondrial functions in vivo and in vitro in rats with carbon tetrachloride-induced liver cirrhosis. J. Hepatol. 33, 216-223.

Kurozumi, R., Takahashi, M., Kojima, S., 2005. Involvement mitochondrial peroxynitrite in nitric oxide-induced glutathione synthesis. Biol. Pharm. Bull. 28, 779-785.

Kus, I., Ogeturk, M., Oner, H., Sahin, S., Yekeler, H., Sarsilmaz, M., 2005. Protective effects of melatonin against carbon tetrachloride-induced hepatotoxicity in rats: a light microscopic and biochemical study. Cell Biochem. Funct. 23, 169-174.
Liu, R.M., Hu, H., Robinson, T.W., Forman, H.J., 1996. Increased gamma-glutamylcysteine synthetase and gamma-glutamyl transpeptidase activities enhance resistance of rat lung epithelial L2 cells to quinone toxicity. Am. J. Respir. Cell Mol. Biol. 14, 186-191. Lowry, O.H., Rosebrough, N.J., Farr, A.L., Randall, R.J., 1951. Protein measurement with the Folin phenol reagent. J. Biol. Chem. 193, 265-275.

Mahesh, A., Jeyachandran, R., Cindrella, L., Thangadurai, D., Veerapur, V.P. Muralidhara, R.D., 2010. Hepatocurative potential of sesquiterpene lactones of Taraxacum officinale on carbon tetrachloride induced liver toxicity in mice. Acta Biol. Hung. 61, 175-190.

Maksimchik, Y.Z., Dremza, I.K., Lapshina, E.A., Cheshchevik, V.T., Sudnikovich, E.Ju., Zabrodskaya, S.V., Zavodnik, I.B., 2010. Rat liver mitochondria impairments under acute carbon tetrachloride-induced intoxication. Effects of melatonin, Biochemistry (Moscow) Suppl. Series A: Membrane and Cell Biology, 4, pp. 187-195.

Manibusan, M.K., Odin, M., Eastmond, D.A., 2007. Postulated carbon tetrachloride mode of action: a review. J. Environ. Sci. Health., Part C Environ. Carcinog. Ecotoxicol. Rev. 25, 185-209.

Markham, K.R., 1975. Isolation techniques for flavonoids. In: Harborne, J.B., Mabry, T.J., Mabry, H. (Eds.), The flavonoids. Chapman and Hall, London, pp. 1-44.

Martinez, J.I., Launay, J.M., Dreux, C., 1979. A sensitive fluorimetric microassay for the determination of glutathione peroxidase activity. Application to human blood platelets. Anal. Biochem. 98, 154-159.

Mitchell, C., Robin, M.-A., Mayeut, A., Mahrouf-Yorgov, M., Mansouri, A., Hamard, M., Couton, D., Fromenty, B., Gilgenkrantz, H., 2009. Protection against hepatocyte mitochondrial dysfunction delays fibrosis progression in mice. Am. J. Pathol. 175, 1929-1937.

Moellering, D.R., Levonen, A.L., Go, Y.M., Patel, R.P., Dickinson, D.A., Forman, H.J., Darley-Usmar, V.M., 2002. Induction of glutathione synthesis by oxidized lowdensity lipoprotein and 1-palmitoyl-2-arachidonyl phosphatidylcholine: protection against quinone-mediated oxidative stress. Biochem. J. 362, 51-59.

Nulton-Persson, A.C., Szweda, L.I., 2001. Modulation of mitochondrial function by hydrogen peroxide. J. Biol. Chem. 276, 23357-23361.

Ohta, Y., Kongo-Nishimura, M., Matsura, T., Yamada, K., Kitagawa, A., Kishikawa, T., 2004. Melatonin prevents disruption of hepatic reactive oxygen species metabolism in rats treated with carbon tetrachloride. J. Pineal Res. 36, 10-17.

Reiter, RJ. Tan, D.X. Terron, M.P., Flores, L.J., Czarnocki, Z., 2007. Melatonin and its metabolites: new findings regarding their production and their radical scavenging actions. Acta Biochim. Pol. 54, 1-9.

Reynolds, E.S., 1963. The use of lead citrate at high pH as an electron opaque stain in electron microscopy. J. Cell Biol. 17, 208-212.

Rodriguez, C., Mayo, J.C., Sainz, R.M., Antolín, I., Herrera, F., Martín, V., Reiter, R.J., 2004. Regulation of antioxidant enzymes: a significant role for melatonin. J. Pineal Res. 36, 1-9.

Rossi, R., Cardaioli, E., Scaloni, A., Ammmiooni, G., Di Simplicio, P., 1993. Thiol groups in proteins as endogenous reductants to determine glutathione-protein mixed disulphides in biological systems. Biochim. Biophys. Acta 1164, 289-298.

Shi, M.M., Kugelman, A., Iwamoto, T., Tian, L., Forman, H.J., 1994. Quinone-induced oxidative stress elevates glutathione and induces gamma-glutamylcysteine synthetase activity in rat lung epithelial L2 cells. J. Biol. Chem. 269, 26512-26517.

Shiryaeva, A., Arkadyeva, A., Emelyanova, L., Sakuta, G., Morozov, V., 2009. Superoxide anion production by the mitochondrial respiratory chain of hepatocytes of rats with experimental toxic hepatitis. J. Bioenerg. Biomembr. 41, 379-385.

Smucler, E.A., 1976. Structural and functional changes in acute liver injury. Environ. Health Perspect. 15, 13-25

Stocks, J., Dormandy, T.L., 1971. The autoxidation of human red cell lipids induced by hydrogen peroxide. Br. J. Haematol. 20, 95-111.

Tang, X.H., Gao, J., Fang, F., Chen, J., Xu, L.Z., Zhao, X.N., Xu, Q., 2005. Hepatoprotection of oleanolic acid is related to its inhibition on mitochondrial permeability transition. Am. J. Chin. Med. 33, 627-637.

Watson, M.L., 1958. Staining of tissue sections for electron microscopy with heavy metals. J. Biophys. Biochem. Cytol. 4, 475-478.

Weber, L.W., Boll, M., Stampfl, A., 2003. Hepatotoxicity and mechanism of action of haloalkanes: carbon tetrachloride as a toxicological model. Crit. Rev. Toxicol. 33, 105-136.

Zavodnik, L. Zavodnik, I., Lapshina, E., Belanovskaya, E., Martinchink, D., Kravchuk, R. Bryshewska, M., Reiter, R.J., 2005. Protective effects of melatonin against carbon tetrachloride hepatotoxicity in rats. Cell Biochem. Funct. 23, 353-359.

Zavodnik, I.B., Lapshina, E.A., Cheshchevik, V.T., Dremza, I.K., Kujawa, J., Zabrodskaya, S.V., Reiter, R.J., 2011. Melatonin and succinate reduce rat liver mitochondrial dysfunction in diabetes. J. Physiol. Pharmacol. 62, 421-427.

Zoccarato, F., Cavallini, L., Alexandre, A., 2004. Respiration-dependent removal of exogenous $\mathrm{H}_{2} \mathrm{O}_{2}$ in brain mitochondria: inhibition by $\mathrm{Ca}^{2+}$. J. Biol. Chem. 279, 166-174. 